\title{
How does AirBnb affect local Spanish tourism markets?
}

\author{
Juan Luis Jiménez ${ }^{1}$ (D) Armando Ortuño ${ }^{2} \cdot$ Jorge V. Pérez-Rodríguez $^{3}$
}

Received: 2 April 2020 / Accepted: 30 July 2021 / Published online: 16 August 2021

(c) The Author(s) 2021

\begin{abstract}
This paper analyses the effects of AirBnb on the size of local tourism markets using AirBnb occupancy rates and hotel overnight stays in order to explore the causal relationship in several Spanish cities. A dynamic panel data model is applied at the city level (2014-2017). Our findings show a positive relationship between the increase in the number of properties offered on AirBnb and the implicit volume of tourists received by each city, specifically in two large cities (Madrid and Barcelona), due to higher AirBnb occupancy rate.
\end{abstract}

Keywords P2P platforms $\cdot$ AirBnb $\cdot$ Tourism demand

JEL Classification $\mathrm{L} 83 \cdot \mathrm{Z} 31 \cdot \mathrm{Z} 38$

\section{Introduction}

The expansion of the "sharing economy" has been based on the development and democratisation of the use of the Internet and the applications necessary to connect the two sides of what are known as two-sided markets. Many of these

Juan Luis Jiménez

juanluis.jimenez@ulpgc.es

Armando Ortuño

arorpa@gcloud.ua.es

Jorge V. Pérez-Rodríguez

jv.perez-rodriguez@ulpgc.es

1 Facultad de Economía, Empresa y Turismo, Universidad de Las Palmas de Gran Canaria, Despacho D. 2-12, 35017 Las Palmas de Gran Canaria, Spain

2 Turismo y Transporte, Departamento de Ingeniería Civil, I.U. del Agua y Ciencias Ambientales e I.U. de Investigaciones Turísticas, Universidad de Alicante, Apartado de Correos 99, 03080 Alicante, Spain

3 Department of Quantitative Methods for Economics and Management, Facultad de Economía, Empresa y Turismo, University of Las Palmas de Gran Canaria, 35017 Las Palmas de Gran Canaria, Spain 
applications are focused on the tourism accommodation market such as AirBnb, HomeAway or Niumba. The former has gained a higher global market share. AirBnb was created in 2008, and by December 2016, it had more than 2 million listings of rental properties 34,000 cities of 191 countries. It had 60 million users and was worth over 22 billion euros (Centre for Global Enterprise 2016).

These applications generate at least two overall positive effects (Farronato and Fradkin 2017): first, the flexible accommodation supply can offer a differentiated product with respect to hotels; second, it can compete with hotels by extending the number of rooms available; a particularly important effect in periods of high temporary demand and in cities with restrictions for extending the hotel supply and with a high market power. However, negative externalities have also been observed, such as the deterioration of the quality of life and the levels of cohabitation of the local population; the increase in housing prices in the long term; or the expulsion of tenants from central areas to peripheral areas (gentrification) (Exceltur 2016; Barron et al. 2017; Zervas et al. 2017).

Tourism scholars are increasingly interested in AirBnb's influence on the tourism industry (Dolnicar 2017). The academic literature on the subject has studied the effects of AirBnb's emergence on the property market (Sheppard and Udell 2016; among others), geolocation and AirBnb (Quattrone et al. 2016, among others), the analysis of the new operator and its drivers (Tussyadiah and Pesonen 2016; among others), and the effect of AirBnb on hotels (Zervas et al. 2017; Farronato and Fradkin 2017; Dogru et al. 2019). In general, the results of these studies reveal price increases in properties for rent or sale derived from the development of AirBnb, and reductions in hotel prices, mainly those of a lower category establishments (see Sect. 2).

Our paper's contribution to the tourism literature is twofold. First, we analyse the effects of AirBnb on several local tourist markets simultaneously in order to respond to two questions considered to be fundamental for a subsequent analysis of public policies: does the increase in the supply of tourist accommodation through these platforms result in an expansion of the local tourism market or does it enter into direct competition with hotels? As this approach has not yet been assessed in Europe, we have analysed a group of cities in Spain rather than focusing on a specific city or region. In other words, we try to explain how AirBnb enlarges domestic tourism markets. More precisely, we have used an unbalanced monthly panel of 31 Spanish cities in the period 2014-2017, which are characterised by different AirBnb penetration rates and types of tourism: city tourism (e.g. Madrid, Seville) and the "sun and beach" product (e.g. Alicante or Palma de Mallorca).

Second, given that this is an aggregate analysis at the city level, we consider two different operators such as AirBnb and hotels, in different cities where competition is also unequal. We therefore focus on how these platforms affect both the AirBnb occupancy rate (based on total booked nights) and hotel overnight stays.

The rest of the paper is organised as follows: The second section summarises the main studies that have analysed this topic. The database and methodology applied are described in the third and fourth sections. The fifth section presents the principal findings of the estimated models. The sixth section discusses the policy implications 
and conclusions of the paper. Finally, the seventh section describes some limitations of the study and proposes future lines of research.

\section{Literature review on the effects of AirBnb}

Many of the reasons for the effects of shared accommodation are explained in the press, blogs or even reports written by AirBnb itself on the subject. ${ }^{1}$ These reports argue that AirBnb's accommodation supply is complementary to the existing hotel supply and that there is a net benefit for travellers visiting cities where the platform operates.

As AirBnb and similar platforms expand around the world, local and regional governments are regulating the entrance of all these new operators (see, for example, Hajibaba and Dolnicar 2017).

In general, as far as we know, and following the potential effects described, the academic studies on this topic can be categorised into four large groups.

\subsection{The most relevant: the effects on the incumbent (the hotel sector)}

How has academic research analysed this aspect and what has it found? Below is a summary of the empirical research and highlights according to the groups listed above.

Although AirBnb itself attempts to show the complementary nature of its supply with the hotels, the recent literature does not confirm these claims. In this way, using detailed information of AirBnb listings, hotels and other characteristics of the geographical area where they are located (unemployment, income, etc.), for the state of Texas (USA) in the period 2008-2014, Zervas et al. (2017) apply an empirical strategy based on the difference-in-difference estimator to estimate this causal relationship. In general terms, these authors raise several relevant points. First, each additional $10 \%$ increase in the size of AirBnb in the market generates a reduction of $0.39 \%$ in the revenue per room of hotels.

Second, the authors attribute this fall in income to both the reduction in the occupancy rate and the reduction in the prices of hotels. The latter is, in fact, a positive change for all users (not only those who participate in the peer-to-peer accommodation).

Third, the entry of this new operator is more relevant in the case of lower category and lower priced hotels (that is, higher category hotels with higher prices are less affected), and independent hotels (the income statements of hotels belonging to a chain are less affected). And finally, they show how, for high demand events (large international fairs, musical and cultural events, etc.), AirBnb confers flexibility to the supply and therefore reduces the market power of the established hotels.

\footnotetext{
1 See https://www.AirBnb.com/economic-impact/.
} 
Recently, Gunter et al. (2020) found similar results. Their spatial econometric approach shows that the demand for AirBnb in New York City is price-inelastic (similar to Gunter and Önder 2018) and income-elastic. The paper also estimates that own-price increases in AirBnb listings in this city do not substantially affect AirBnb demand, but increases in hotel prices and tourist income do. Finally, they conclude that AirBnb listings in New York City are substitutes for the traditional accommodation industry, especially in Manhattan.

For the European case, Neeser (2015) studies the effect of AirBnb on the hotel industry in Norway, Finland and Sweden. He finds that it contributes to a reduction in the average price of hotel rooms. Coyle and Yeung (2016) focus on 14 cities and find that AirBnb's presence in a market has a negative effect on hotel occupancy rates but a positive effect on total hotel revenue and the average daily rate they charge.

Farronato and Fradkin (2017) carry out a theoretical exercise which they empirically validate using detailed monthly information about hotels and AirBnb for the 50 largest cities of the USA during the period 2011-2014. They find that AirBnb has a price elasticity of supply that is double that of the hotels. According to the authors, this result is due to the lower flexibility of the hotels to adapt to the cyclical fluctuations of the demand in each city and the restricted capacity of the hotels compared to the peer-to-peer accommodation.

Moreover, coinciding with the results of Zervas et al. (2017), these authors find a negative relationship between the revenue of the hotels and the presence of AirBnb in the cities, whereby a $10 \%$ increase in AirBnb's accommodation supply reduces hotel revenue by $0.36 \%$. The most relevant and newest finding is that the existence of AirBnb has given rise to an increase in the consumer surplus, although the users of this platform benefit less from this surplus than those who stay in hotels.

Finally, Farronato and Fradkin (2017) find that the share of AirBnb is greater in cities where prices are higher, which is due to the market power exercised by the hotels. This is why the entry of these new competitors generates an even more negative effect on the revenue of the hotels. However, the authors conclude that the net effect of this peer-to-peer accommodation economy model will depend on the consequences derived from its existence on the labour and property markets and the neighbours of AirBnb properties, none of which are contemplated in their analysis.

Continuing with the competition between hotels and this type of rental property, with a sample of more than 800 tourists who had used the AirBnb platform to book their accommodation, Guttentag and Smith (2017) observed that those with a low level of income used AirBnb as a substitute for hostels and low-category hotels, while those with higher incomes and families with children used AirBnb as a substitute for Bed and Breakfasts and medium- and high-category hotels. Furthermore, almost $65 \%$ used AirBnb as an alternative to hotels in the intermediate category. With respect to the induced demand, $2.3 \%$ expressed that they would not have travelled if this platform did not exist, while more than $25 \%$ indicated that the choice of this type of accommodation would determine a longer stay in the destination.

Dogru et al. (2019) examine the effects of the AirBnb supply on room revenues (RevPAR), average daily rates (ADRs) and occupancy rates (OCC) in ten major US hotel markets for the period between July 2008 and June 2017. Their results show 
that an increasing AirBnb supply has a negative impact on all three performance metrics. Moreover, it provides evidence of AirBnb's growing impact on the mainstream market across hotel class segments, signalling a high level of consistency with the tenets of the theory of disruptive innovation.

\subsection{Incidence of the entry of AirBnb into the property market}

The second group includes those studies that focus on the incidence of the entry of AirBnb into the property market. In general, these papers found a positive effect of AirBnb on prices, i.e. an increase in localized AirBnb availability is associated with an increase in property values.

For example, Sheppard and Udell (2016) find that a doubling of AirBnb listings is associated with increases of $6 \%$ to $11 \%$ in house values, ceteris paribus. Using a difference-in-difference approach produces an even larger estimated impact, suggesting that properties that listed on the AirBnb platform increase in value by about $31 \%$. These results indicate that the consequences of this platform in welfare should be evaluated.

Other papers on this topic include Horn and Merante (2017), Barron, Kung and Proserpio (2017) or Coles et al. (forthcoming).

\subsection{Geolocation and geographical distribution}

A third group of studies includes those that analyse the geolocation of AirBnb and the geographical distribution of its listings across cities. As Eugenio-Martín et al. (2019) state, although population size and the number of tourist visits matter as determinants of AirBnb location, the main determinant is price. Regarding geographical considerations, AirBnb supply overlaps that of established hotels in city tourism, but it does not do so as clearly in sun and beach or nature-based destinations.

Other papers on this topic are Quattrone et al. (2016), Gutiérrez et al. (2017),Adamiak (2018), ${ }^{2}$ Heo et al. (2019) or Gyódi (2019).

\subsection{The new operator and its drivers}

The final group is a miscellaneous group of studies that seek to analyse the new operator and its drivers (Tussyadiah and Pesonen 2016; Wang and Nicolau 2017; Gurran and Phibbs 2017; Wegmann and Jiao 2017; Volgger et al. 2019; among others).

In this group, the study of Nowak et al. (2015), with a sample of more than 4000 tourists from four countries (USA, UK, France and Germany), concludes that $4 \%$ of the tourists would not have travelled if this platform did not exist. The same study

\footnotetext{
${ }^{2}$ He provides a generic spatial description of AirBnb supply across European cities, by using data from December 2017.
} 
questions whether the competition with hotels is that high, as $42 \%$ of the tourists would be substituting hotels, while $36 \%$ Bed and Breakfasts, $31 \%$ the homes of relatives and around $20 \%$ rental apartments.

With respect to established companies (hotels), academic papers state that the new operator constitutes a competitor, particularly for lower-category hotels and those that do not belong to a hotel chain. However, with respect to the objective of this study, there are no studies on how AirBnb has increased (if this is what it has done) the volume of tourists received by the destinations where it is established, given that the attempts made have not gone beyond percentage estimates of induced demand based on surveys, as is the case of Nowak et al. (2015) or Guttentag and Smith (2017).

Finally, regarding the selected method to evaluate these effects, the empirical literature has shown alternative methods to analyse the impact of AirBnb in several cities. For example, the phenomenon has been analysed from both quantitative and qualitative perspectives. With regard to quantitative methods, we can refer to studies that examine the hedonic prices of AirBnb in several European cities (Ert and Fleischer 2019), the use of logistic regression models explaining AirBnb and non-AirBnb peer-to-peer accommodation in Australia (2015-2017) (Volgger et al. 2019), the effectiveness of user-generated content and marketer-generated content on consumer purchasing decisions (Lian et al. 2020) using multilevel regression models, or the analysis of the consumer behaviour of users of AirBnb and hotels based on structural equation models and qualitative analysis with structural associations (Huarng and $\mathrm{Yu}, 2019)$. On the other hand, with respect to qualitative methods, we can highlight the theoretical framework of the intercultural host-guest relationship (Chang and Hang 2019), the construction of home feeling by AirBnb guests in the sharing economy using a semantic perspective (Zhu et al. 2019) or the analysis of the impact of AirBnb on residents (Jordan and Moore 2018).

In summary, our paper falls within in first group and, as far as we know, none of previous papers attempt to explain how AirBnb enlarges domestic markets, which is our objective in this paper.

\section{Data and variables}

The database has a monthly panel data structure, and the city is the unit of observation. Specifically, this unbalanced panel includes a total of 31 Spanish cities ${ }^{3}$ for which information is available for the period August 2014-October 2017, with

\footnotetext{
3 The cities included, in alphabetical order, are: A Coruña, Alicante, Barcelona, Bilbao, Cáceres, Cádiz, Castellón, Córdoba, Gijón, Granada, Las Palmas de Gran Canaria, León, Logroño, Madrid, Málaga, Murcia, Oviedo, Palma de Mallorca, Pamplona, Salamanca, San Sebastián, Santa Cruz de Tenerife, Santander, Santiago de Compostela, Seville, Tarragona, Toledo, Valencia, Valladolid, Vigo and Zaragoza.
} 
different frequencies and availability of data. ${ }^{4}$ In general terms, this is a small panel data sample.

The cities have been selected according to the Survey on Tourist Attractions of the Spanish National Statistics Institute due to the need for complementarity with this information source. According to the population data of 2016, these cities have over 13 million registered inhabitants, representing 28.3 per cent of the total Spanish population at that date (Spanish National Statistics Institute -I.N.E.- 2019).

The information contained in the database can be categorised into three groups of variables depending on the content and sources used: (1) local accommodation supply of AirBnb; (2) indicators of demand and local hotel supply from a sample and different sources; (3) socio-economic characteristics of the city and others. Specifically, the variables for each city are ${ }^{5}$.

(i) Occupancy rate of the AirBnb supply. Average level of occupancy per month and per city. This is calculated by Airdna following the relationship: total booked nights/(total booked nights + total available days).

(ii) ADR (average daily rate) per month and per city (for AirBnb) in euros. Source: Airdna.

(iii) RevPar (Revenue per available room). This is a relative income, when divided by the number of beds, thereby producing an average daily rate per bed, with the same periodicity (ADR/beds). It has been included only for the purpose of descriptive analysis in this paper (see "Appendix 1"). Source: Airdna.

(iv) AirBnb total beds per month and per city. Source: Airdna.

(v) Total number of properties. Total number of properties (supply) offered by AirBnb that are available per month and per city. Source: Prepared by the authors based on Airdna.

(vi) Total hotel beds. Number of total beds available, per month and city. Source: The Spanish National Statistics Institute's hotel occupancy survey (Encuesta de Ocupación Hotelera).

(vii) Hotel overnight stays. It is the total overnight stays by tourists lodged in hotels, per month and city. Source: The Spanish National Statistics Institute's hotel occupancy survey. Two questions: this variable controls that some hotels are closed during the low tourist season and, again, it is a sample. ${ }^{6}$

(viii) Foreign hotel customer rate. Percentage of foreign hotel customers with respect to total customers (residents plus foreign ones). Source: Own elaboration from the Spanish National Statistics Institute's hotel occupancy survey (Encuesta de Ocupación Hotelera).

\footnotetext{
${ }^{4}$ In particular, the date when the company Airdna began to gather data on AirBnb's activity was January 2016, except: Barcelona (August, 2014), Cádiz (November, 2015), Madrid (August, 2014), Málaga (September, 2014), Pamplona (September, 2015), San Sebastián (September, 2014), Seville (September, 2014), Valencia (September, 2014).

5 A more detailed descriptive analysis can be found in Ortuño and Jiménez (2019).

6 These variables are obtained from the "Encuesta de Ocupación Hotelera". It is made by Spanish Statistics Institute (INE). Database is here: https://www.ine.es/dynt3/inebase/index.htm?padre=238\&capsel= 238
} 
Table 1 Descriptive statistics. Source: Own elaboration

\begin{tabular}{llrrrrr}
\hline Variable & Units & Obs & Mean & S.D & Min & Max \\
\hline AirBnb total beds ${ }^{(1)}$ & Number of beds & 785 & 1201.62 & 9146.95 & 4.00 & $60,373.17$ \\
RevPar (ADR/bedroom) & Euros per bedroom & 737 & 43.80 & 13.70 & 14.50 & 110.20 \\
AirBnb occupancy rate & Percentage & 771 & 21.59 & 21.09 & 0.96 & 68.15 \\
$\quad(\times 100)$ & & & & & \\
Total number of properties & Number of properties & 737 & 7.60 & 7.60 & 1.00 & 49.00 \\
Hotel total beds & Number of beds & 753 & 7728.00 & $17,336.98$ & 2022.00 & $84,135.17$ \\
Foreign hotel customers rate & Percentage & 753 & 37.90 & 20.26 & 6.49 & 94.02 \\
Overnight stays (hotels) & Number & 753 & $206,289.8$ & $369,736.4$ & 10,375 & $2,078,832$ \\
Trivago hotel price index & Euros per room & 754 & 86.10 & 25.20 & 56.00 & 209.00 \\
Hotel room occupancy rate & Percentage & 753 & 54.38 & 15.89 & 22.02 & 93.44 \\
$\quad(\times 100)$ & & & & & & \\
\hline
\end{tabular}

Obs. = Observations; S.D. = Standard deviation; Min and Max are the minimum and maximum. ${ }^{(1)}$ The large deviation of this variable is due to the fact that the database includes different cities in different stages of AirBnb's expansion

(ix) Hotel price. There is no official database for hotels that contains a complete range of information, unlike the case of AirBnb. For this reason, the Trivago hotel price index has been used (despite its name it is not actually an index). This is prepared by the company on a monthly basis and refers to the average price per night (euros) in a standard double room in each city for all the hotels included on this website. We should point out that this is not real average data (unlike ADR for AirBnb) but a sample. ${ }^{7}$ It is noteworthy that data on hotel prices do not necessarily match data on demand and supply. (This is a limitation of our paper.)

Table 1 includes the descriptive statistics of the database for the principal variables used in the study. As we can see, there are favourable differences for hotels in average terms. For example, we can observe high differences between AirBnb and hotel total beds (1202 and 7728, respectively), but also in terms of the average occupancy rates (21.59 and 54.38, respectively).

Figures 3, 4, 5, 6 (see "Appendix 1") describe AirBnb's expansion in each city but from the perspective of the total number of beds offered; this variable is compared with that obtained through the INE for hotels called "Estimated number of beds". It should be noted that some of the variables analysed, such as ADR/bedroom (RevPar), AirBnb occupancy rate, Tourists, Hotel room occupancy rate and Hotel price index (Trivago) imply seasonality. There are considerable differences among cities, ${ }^{8}$ but in general no decrease in the hotel supply can be observed as a result of the increase in the AirBnb supply.

\footnotetext{
7 For more information, see: https://businessblog.trivago.com/trivago-hotel-price-index/.

8 The data of estimated hotel beds for Palma de Mallorca show this variability for 2017 in the original data source (INE). It is assumed that this deviation is due to the closure of hotels during the low season.
} 


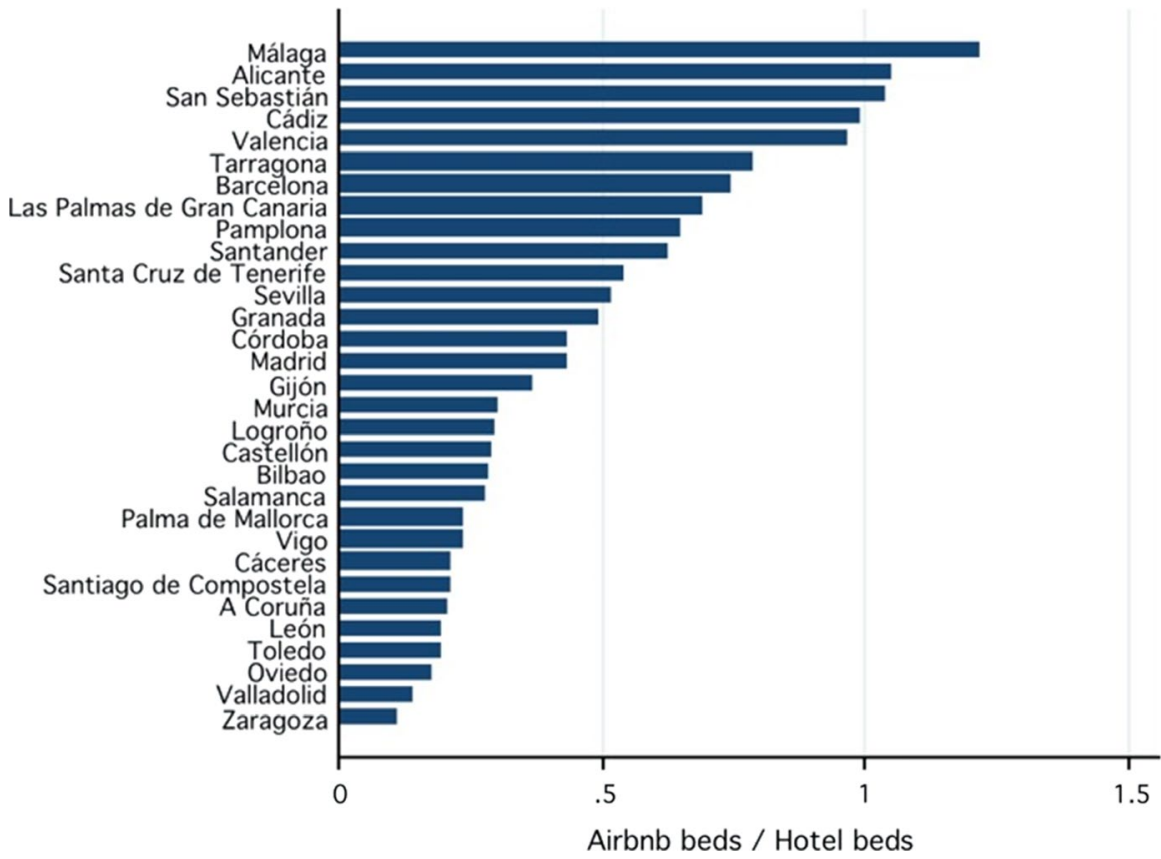

Fig. 1 Supply of AirBnb beds with respect to hotel beds. October 2017. Source: prepared by the authors based on data drawn from Airdna and I.N.E
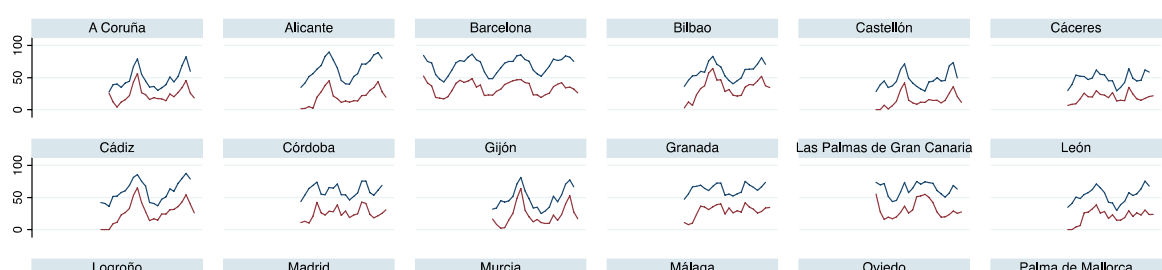

Las Palmas de Gran Canaria
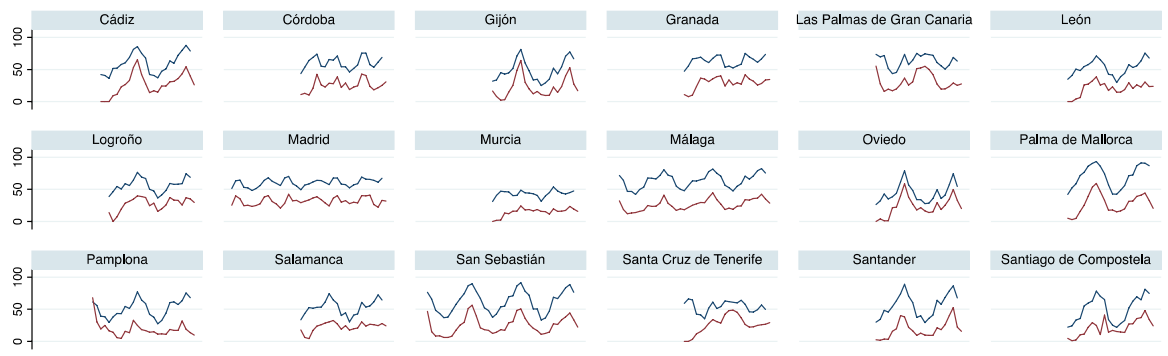

Santa Cruz de Tenerife
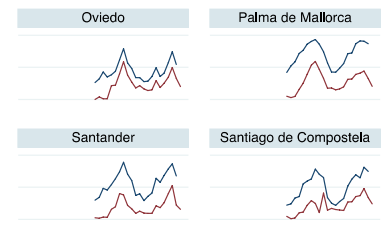

Santiago de Compostela
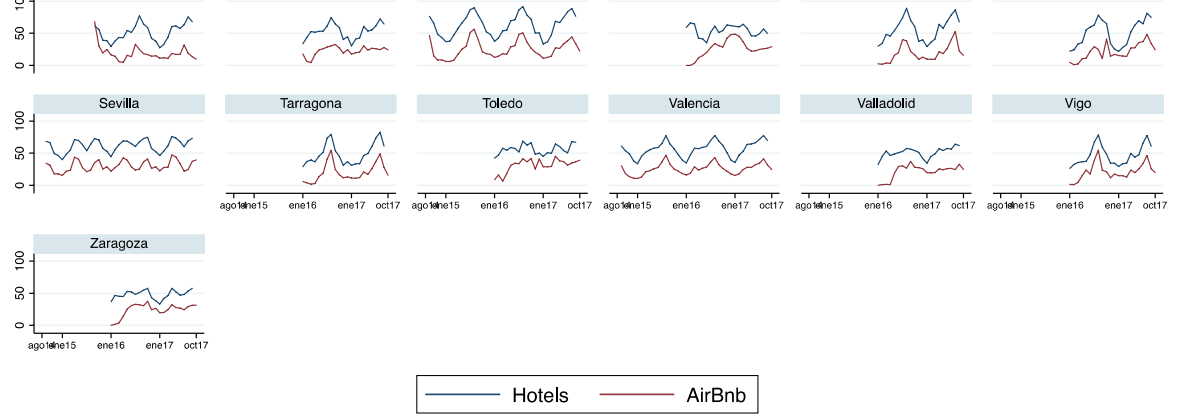

Fig. 2 Hotel and AirBnb occupancy levels by city (August 2014-October 2017). Source: prepared by the authors based on data drawn from Airdna and I.N.E 
Figure 1 is an ordered summary of the ratio of beds offered by AirBnb versus hotel beds by city with data from October 2017. The cities with the highest penetration of AirBnb with respect to the hotel supply at the end of 2017 are Málaga (AirBnb beds are 121\% of hotel beds), Alicante (105\%) and San Sebastián (103\%). At the opposite end of the ranking, we can find Oviedo (17\%), Valladolid (14\%) and Zaragoza (11\%). Overall, the most significant feature of the penetration of this model is the growth of this ratio. Therefore, in October 2016, the average ratio was $32 \%$ (range of 7-89\%) and one year later it was $50 \%$ higher at $48 \%$ (range of $11-121 \%)$.

But, how are hotels and holiday rentals occupied? Figure 2 shows the evolution over time for each city of the level of hotel occupancy by beds and of the occupancy ratio of AirBnb. We can observe how the peaks and troughs of hotel occupancy coincide with those of AirBnb, showing a linear correlation coefficient of 0.78 for the whole period when all of the cities are included. In other words, the behaviour patterns are very similar. However, it is noteworthy that, in general, there are two dynamic characteristics in these variables: seasonal patterns and trend.

In addition, in all cases (except for Pamplona at the beginning of 2016), the hotels reveal higher levels of occupancy with an average rate of $56 \%$ for the 40 months studied, whereas the average rate for AirBnb properties was $25 \%$. In Fig. 2, we can see how the hotel occupancy levels have remained stable in general despite the increase in the AirBnb supply, although a quantitative analysis would be able to answer this question more precisely.

In this descriptive analysis of the principal statistics relating to AirBnb and the hotel supply, it is interesting to assess the behaviour of the prices of the two types of supply. Although the indicators for them are not perfectly comparable, they do allow us to evaluate the relationship between the two (at least descriptively) and the trend of the series. ${ }^{9}$

From Figures 7, 8, 9, 10 (see "Appendix 1"), we can draw three main points. First, the ADR per room is lower than the prices offered by Trivago (an obvious aspect which constitutes one of the principal advantages of these new suppliers). Second, the seasonality of hotel prices is much more pronounced than in those of the AirBnb properties, except for specific periods (probably associated with extraordinary events such as the Mobile World Congress in Barcelona or the Gay Pride festival in Madrid). And, finally, both series show a growth trend. In any event, the casuistry for each city is broad.

\footnotetext{
9 The comparability is restricted to a weak assumption, from our point of view; the price index of Trivago contemplates the average price per night in a standard double room while the ADR (Average Daily Rate) for the AirBnb properties is obtained per room, which we assume to have two beds. In any event, the analysis should not necessarily be carried out in terms of quantity but in terms of trends.
} 


\section{Methodology}

We use a demand model such as Gunter et al. (2020) to assess how AirBnb enlarges domestic markets. More specifically, we use an autoregressive model for occupancy rates (as a measure of AirBnb demand) in a panel data framework. However, unlike Gunter et al. (2020), who study the effects on New York, we do not formulate a spatial panel data model, but consider several cities.

We create a dynamic panel data model with two-way fixed effects based on the following facts. First, we incorporate the dynamic and changing nature of occupancy rate and overnight stays as a regressor (state dependence in our empirical context), based on the following twofold rationale. On the one hand, this is consistent with the tourist expectations and habit persistence, but also if a partial adjustment mechanism is postulated to allow for rigidities in supply (Song and Witt 2000). Also, it can be consistent with the process of adjusting to a long-run steady state when using aggregate data (García-Boto 2020). AirBnb is a new market (or at least it was at the time of analysis) and its expansion could depend on how it works previously. That is, it is not in a stationary state. García-Boto et al. (2020) explain that the tourism consumption of a given month depends on previous months. Therefore, both AirBnb occupancy rates and hotel overnight stays may depend on the information of the variable in the previous period because they are autocorrelated. Furthermore, the autocorrelation is expected to be positive.

On the other hand, it can be assumed that past occupancy rates (or overnight stays) can help forecast current occupancy rates, such that previous behaviour influences current behaviour. Zhang et al. (2018) pointed out that an accurate prediction may be useful for formulating strategic policies and the sustainable development of tourist destinations, since it would allow adequate resources to be allocated to support hotel operations. In addition, from a business point of view, occupancy forecasting can help in marketing decision-making and revenue management practices.

Second, the existence of unobserved heterogeneity could induce spurious dependence if it is not taken into account (Heckman 1981a,b). To avoid spurious state dependence, we formulate a two-way fixed-effects dynamic panel data model that controls for unobserved heterogeneity in the form of city fixed effects and time fixed effects. Our model also includes factors that drive demand and supply in AirBnb but also in hotels. This is a supply-demand-driven model.

Hence, the general dynamic model for the 31 Spanish cities over the period 2014-2017 can be written as:

$$
\begin{aligned}
\log y_{i t}=\beta_{0} & +\sum_{j=1}^{p} \alpha_{j} \log y_{i t-p}+\beta_{1} \log \mathrm{ADR}_{i t}+\beta_{2} \log \mathrm{THPI}_{i t}+\gamma^{\prime} Z_{i t} \\
& +\sum_{k=2}^{12} \delta_{k} d_{k t}+\pi_{1}\left(\mathrm{NC}_{i t} \times S_{i t}\right)+\lambda_{i}+\eta_{t}+v_{i t}
\end{aligned}
$$

where log is the natural logarithm, $y_{i t}$ represents the endogenous variable of interest (e.g. the AirBnb occupancy rate and overnight stays for hotels in the $i$-th city and period $t$, respectively) and $y_{i t-j}$ is both the lagged endogenous variable for the $j$-th 
period $(j=1, \ldots, p) . \mathrm{ADR}_{i t}$ is a measure of the AirBnb price in the $i$-th city and period $t$, and THPI $_{i t}$ is a Trivago hotel price index as a measure of competitors' prices from the traditional accommodation industry, given that we cannot obtain data on the ADR of hotels in each city.

$Z_{i t}$ is a vector that incorporates other explanatory variables. We included three variables as $Z_{i t}$. The variable AirBnb total beds refers to the total number of beds offered in the $i$-th city at period $t$ and reveals a high correlation (over 0.95 ) with the number of AirBnb properties per city, so they are both proxies for the same effect. The variable Hotel total beds is also included and refers to the estimated hotel supply at the same level (city and month). These two variables have been incorporated as quadratic variables in order to estimate potential nonlinear effects. Moreover, we include the ratio of foreign hotel customers in order to control for potential income effects.

We also include the seasonal dummy $d_{k t}$, which takes the value of 1 in month $k$ (January to December) and 0 otherwise. Seasonal dummies account for deterministic seasonality. We omit $k=1$ because we assume that January is the reference category. Also, Fig. 2 seems to suggest that northern cities have peaks in summer, while the rest have a different pattern. Therefore, we create a northern cities dummy (which take the value of one if the city referred to is A Coruña, Bilbao, Gijón, Oviedo, Santander, Pamplona and Vigo) and interact it with the summer month dummies (which take value 1 for the months July-August-September) in order to address this asymmetry. $\lambda_{i}$ refers to city binary variables and represents all sources of unobserved heterogeneity in the cities. This is the panel-level effect representing the unobserved individual heterogeneity for each city, which can be correlated with the covariates and varies between cities. Certain city-specific factors must be considered in our case, such as a different income effect, effects of international airline routes, an unbalanced tourism composition, and similar. $\eta_{t}$ are the year fixed effects corresponding to the years 2015, 2016 and 2017, respectively (year 2014 is the reference category).

The variable $v_{i t}$ is a disturbance term with null mean and constant variance, $\sigma_{v}^{2}$, and is uncorrelated with the regressors. Finally, $\beta_{0}, \alpha_{j}(j=1, \ldots, p), \beta_{1}, \beta_{2}, \gamma^{\prime}$, $\pi_{1}, \delta_{k}(k=2, \ldots, 12)$ are unknown parameters to be estimated, besides city fixed $\lambda_{i}(i=2, \ldots, 31)$ and year fixed effects $\eta_{t, \text { year }}$ (year $\left.=2015,2016,2017\right)$, which in the case of coefficients for independent variables in logs are directly interpreted as short-run elasticity. For example, $\beta_{1}$ is the short-run own-price elasticity (ADR) for AirBnb occupancy rates. Although the time period is short, this model also provides us with a first impression of the short- and long-run demand elasticities, which may have policy implications for both AirBnb managers and the hotel industry, but also for policy makers. To estimate the long-run elasticity of ADR, we must build the ratio: $\beta_{1} /\left(1-\sum_{j=1}^{p} \alpha_{j}\right)$.

It should be noted that to complete the demand model we must include tourist income data weighted by source market. However, as there are no public data available on the nationalities visiting each city, it is not unreasonable to assume that the nationalities of tourists who visit Spanish cities are relatively similar; hence, the 
time-fixed effects could approximate a common aggregate income for these nationalities as it is time-variant and city-invariant.

To estimate Eq. (1), we consider two situations. First, we estimate it through two classic panel data estimators considering $\alpha_{1}=0$ (i.e. no autocorrelation or nostate dependence). We use the classic fixed-effects estimator and the fixed effects with instrumental variables to allow for the endogeneity of prices and supply. We then estimate the dynamic panel data model using the Arellano and Bond estimator (1991) and the Blundell and Bond (1998) system estimator; these constitute a practical way to control for unobserved heterogeneity and tackle the endogeneity problem, as the lagged dependent variable is correlated with the individual effect by first differencing and using the lagged levels and lagged differences as instruments. These methods apply additional moment conditions and obtain a more efficient estimation of the parameters than the Arellano and Bond estimator (1991). (The ratio of the variance of the panel-level effect to the variance of idiosyncratic error is large.) Both estimators are GMM-type, allowing the endogeneity of prices to be considered.

We also jointly test the influence of the state of dependence and the unobserved heterogeneity in the form of city-specific and year-specific fixed effects.

In general, we expect the past AirBnb occupancy rate or hotel overnight stays to have a significant positive impact on the current occupancy rate and overnight stays due to the repetition effect on the trips that tourists usually make (the higher the income, the greater the effect) (see Boto-García 2020, for the Spanish case). We also assume the price elasticity of AirBnb demand to be negative (a normal good) and the cross-price elasticity of AirBnb demand with respect to hotels to be positive if they are substitute good, such as previous empirical literature on this topic has shown. Finally, in terms of supply variables, we expect positive effects of AirBnb beds on occupancy rates. If the latter is confirmed, we can conclude that this platform expands local tourist markets, if this positive effect outweighs the potential negative effect on hotels.

\section{Results}

In this section, we explain the main results from the AirBnb occupancy rates and hotel overnight stays, but also we analyse the long-run elasticities obtained from both models. 


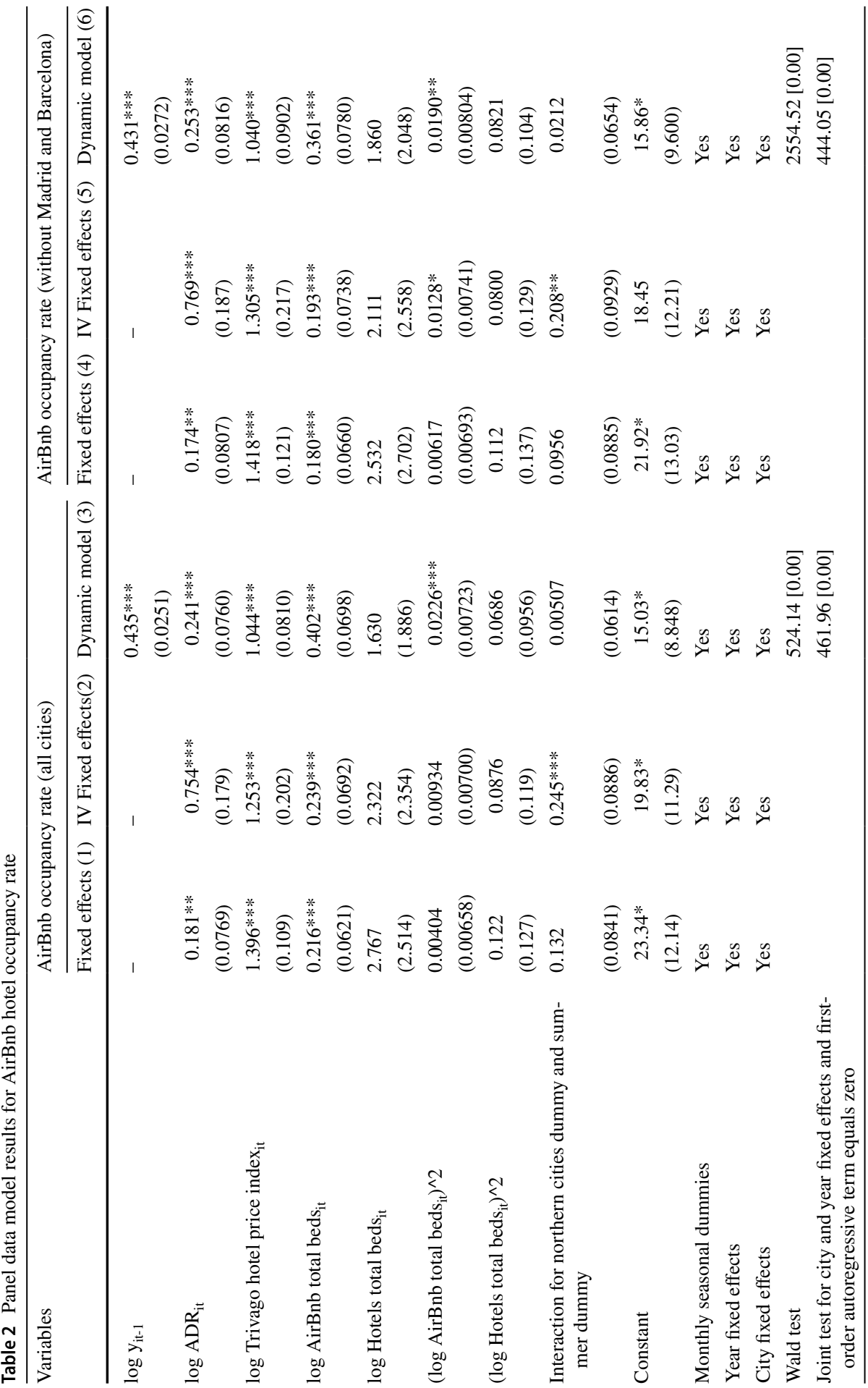




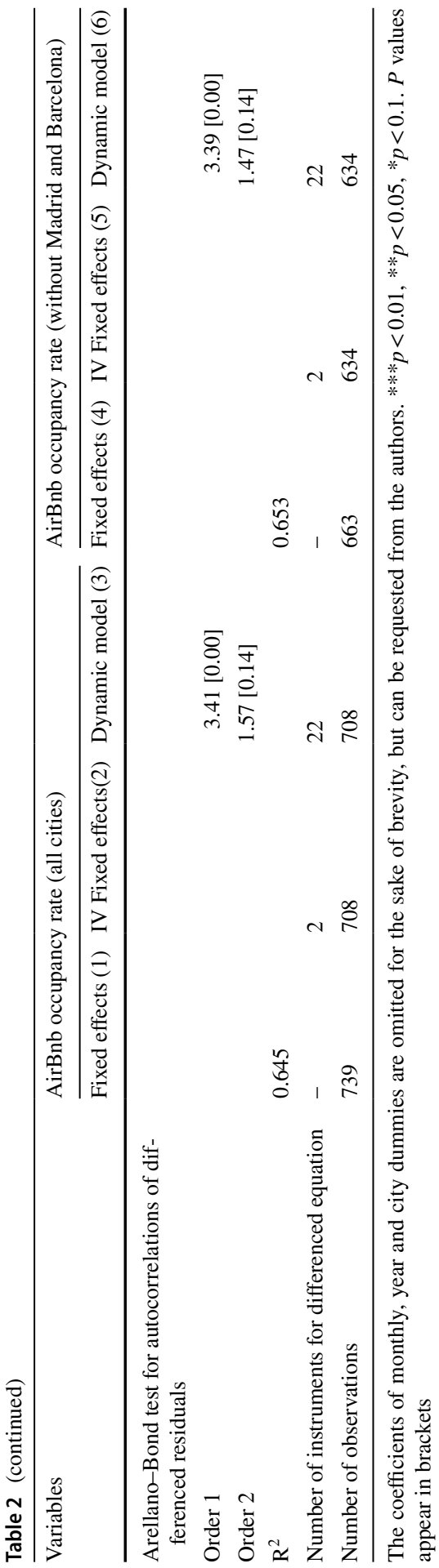




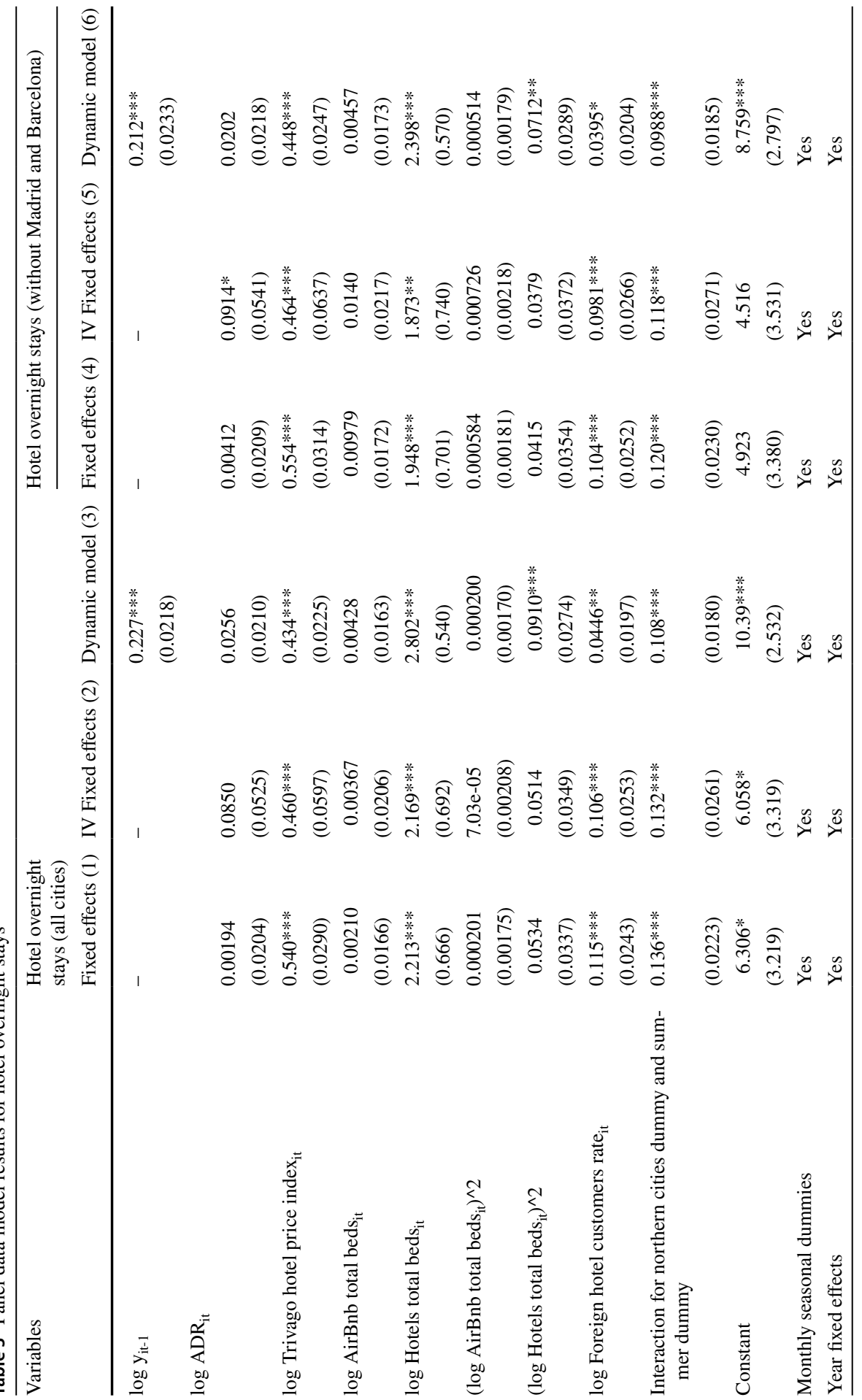




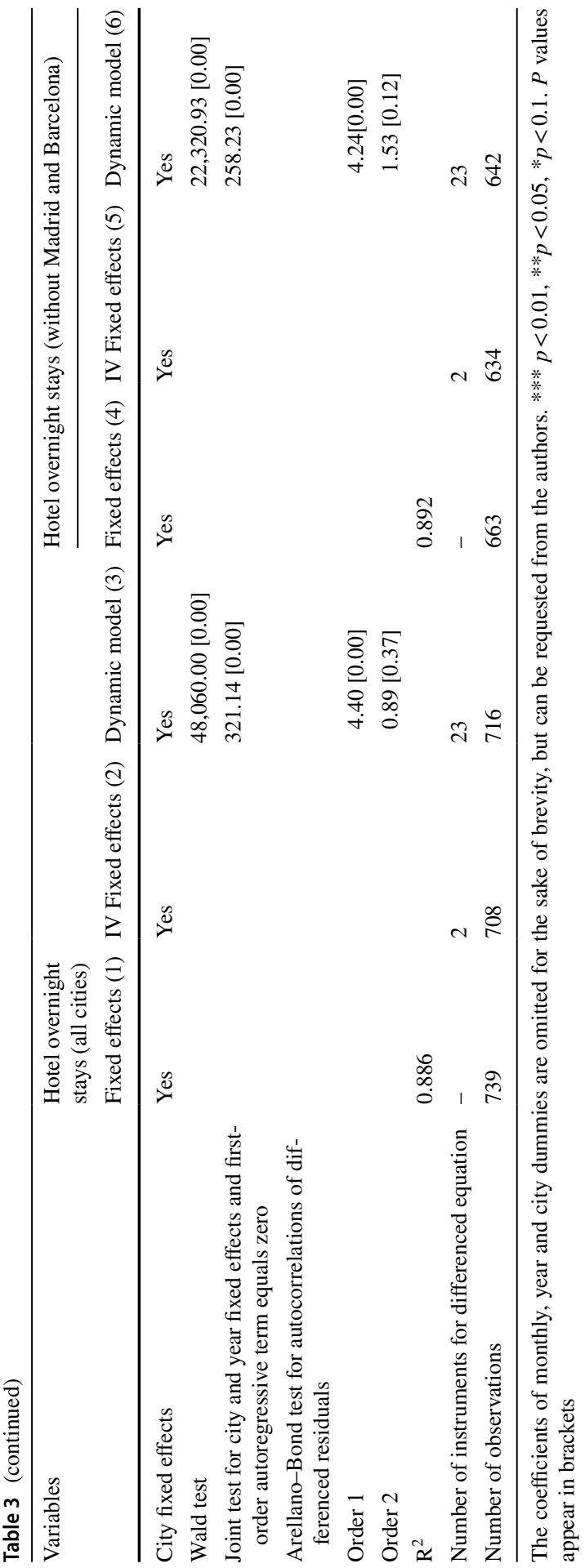




\subsection{AirBnb occupancy rate model}

Table 3 shows the coefficient estimates and the p-values for the panel using Eq. (1) and the previously defined empirical strategy. ${ }^{10}$ We use occupancy rates in terms of total booked nights for AirBnb, considering two models: one includes all cities and another excludes the cities of Madrid and Barcelona, which are the two major cities in Spain where the phenomenon of AirBnb is most relevant. For both occupancy rates, we estimate three models for comparative purposes: the classic fixed-effects estimator or least-squares dummy variable estimator (models 1 and 4 in Table 2), the instrumental variable fixed-effects estimator, which uses the two-stage least-squares within the estimator (where we use lagged prices as instruments (models 2 and 5) and the dynamic panel data model using the Blundell and Bond (1998) estimator (models 3 and 6). This last method assumes that there is no autocorrelation in the idiosyncratic errors and requires the initial condition that the panel-level effects be uncorrelated with the first difference of the first observation of the occupancy rate. It should also be noted that we include the city and year fixed effects and monthly dummies (as in Eq. (1)). Also important is that we select one lag for the occupancy rate as regressor $(p=1)$, as higher orders are not statistically significant.

Table 2 also shows the $R^{2}$ for the classic fixed-effects models, the number of instruments for instrumental variable estimators. We include three types of tests for the dynamic panel data model: the Wald test or joint test for the null hypothesis that coefficients of the model are zero, excluding the constant; the joint test for the null hypothesis that city fixed effects and the first-order autoregressive term (state dependence) are equal to zero; and the Arellano-Bond test for autocorrelations of differenced residuals. The Blundell-Bond estimator assumes that there is no secondorder autocorrelation in the composite errors. We also include the Arellano-Bond test for zero autocorrelation in first-differenced errors. The null hypothesis is that there is no autocorrelation. Specifically, we include the statistics for the test to determine whether the autocorrelation of order 1 is 0 and that of order 2 is 0 , respectively. This statistic is distributed as N(0,1). Finally, we specify the number of total observations used in the estimation for all models.

The dynamic panel data results are obtained by applying the Blundell-Bond robust GMM estimator, taking into account the endogeneity of certain regressors such as ADR and the Trivago price index. The instruments for the differenced equation and level equation are also used.

In general, the results from fixed effects (models 1 and 4), instrumental variable fixed effects (models 2 and 5), and dynamic panel data models (models 3 and 6)

\footnotetext{
10 Although the time period is short, we use panel unit root tests on the variables used in Eq. (1). The results (which can be requested from the authors) reject the null hypothesis in most cases. We therefore use the stationary panel data model defined by Eq. (1) instead of cointegration analysis. It is also worth noting that if the variables were non-stationary, an adequate framework with a longer time span we could apply the nonstationary heterogeneous panel methodology proposed by Pesaran et al. (1997, 1999) to estimate long-run relationships in dynamic heterogeneous panels, as we are using a panel time-series with a large number of periods.
} 
show that the majority of parameters have similar signs for the variables of interest and similar values in magnitude.

Focusing on the results of the estimated coefficients in models $1-3$, in general, we can state the following. Given that the coefficient for the log dependent variable lagged by one period (first-order autocorrelation or state dependence) is positive (and less than 0.5 ) and statistically significant at any level of significance; that $\left|\hat{\alpha}_{1}\right|<1$ (our dynamic model is a stationary process); and that the joint hypothesis that all city and year fixed effects and first-order autoregressive term are zero $\left(\alpha_{1}=0\right)$ (no state dependence and no fixed effects) is rejected at the 5\% significance level in the AirBnb occupancy rate model, we will focus our explanation on this model. $^{11}$

The result for the dynamic model is correct in terms of the Arellano-Bond test for zero autocorrelation in first-differenced errors. Specifically, autocorrelations of order 1 are statistically significant, and autocorrelations of order 2 are not statistically significant at the $1 \%$ significance level in the model. The Wald test for the joint hypothesis that all coefficients (excluding the constant term) are zero is rejected, indicating that the model is suitable.

Taking into account the above considerations, we analyse some results in the model which explain the AirBnb occupancy rate. First, an interesting point is that it shows that the growth in the accommodation supply due to AirBnb's activity in the cities produces an increase in the occupancy rate. This relationship is nonlinear, due to the negative and statistically significant coefficient of the quadratic term. Specifically, in the dynamic panel data model (model 3), a 1\% increase in total AirBnb beds generates around a $0.081 \%$ (slight) increase in the total tourist occupancy rate, evaluated at the mean of the AirBnb total beds logarithm. ${ }^{12}$ In other words, the more AirBnb firms that are listed, the greater the number of local tourists in the city.

Second, the estimated coefficients for prices confirm our expectations: a negative elasticity between the AirBnb occupancy rate and own prices (less than one, or price-inelastic in the short term). Finally, it should also be noted that the coefficients of the seasonal dummies that account for deterministic seasonality are positive and statistically significant, with the highest value corresponding to August. ${ }^{13}$ Moreover, the coefficient for the binary variable for Northern cities in the summer months is also positive and statistically significant, indicating that there are different patterns (peaks) in the summer for northern cities in both occupancy rates and overnight stays, respectively.

Finally, an interesting question to consider is: what is the effect of AirBnb if we omit the more important Spanish cities (Madrid and Barcelona)? It is worth noting that the descriptive analysis reveals that they are the two most relevant cities in our

\footnotetext{
11 Although not shown, it is worth noting that the system estimator produces a slightly higher-level estimate in two of the models considered (3 and 6). This also coincides with the results of Blundell and Bond where the system estimator does not have the downward bias that the Arellano-Bond estimator has when the true value is high.

12 This is the result of the calculation: $\hat{\gamma}_{1}+2 \hat{\gamma}_{2} \overline{\log \text { beds }}$, where $\overline{\log \text { beds }}$ is the average of log beds.

13 These results are not shown for the sake of brevity but can be requested from the authors.
} 
sample with respect to the expansion of AirBnb (except for Málaga). For this reason, we have estimated the same models as for all cities in Table 2 without including these cities (columns 4-5). In this case, the main result regarding the size of the coefficients for AirBnb beds is very similar to columns 1-3 in Table 2.

In summary, these results show that AirBnb creates its own demand.

\subsection{Hotel overnight stays model}

Table 3 shows the results for hotel overnight stays using the same specifications as in Table 2 (occupancy rate is not used due to potential endogeneity problems). Focusing on the results for the dynamic model, it is remarkable that our results for hotels are not in line with the empirical literature. In general, the results for the hotel overnight stays do not allow us to respond to the question of how the increase in market size has been managed by the hotels. In this model, the entry of this new player (AirBnb) has given rise to an effective competitor for them and the question is whether it has affected their level of occupancy.

The results show that the number of AirBnb beds does not affect hotel overnight stays. For this reason, we have found neither substitution nor complementarity effects in this relationship.

Regarding the effect of prices, model 3 reveals a positive relationship between AirBnb prices on the hotel overnight stays, but it is only statistically significant in model (5), and therefore, we cannot talk about a substitution effect. Nevertheless, we also find a positive own-price relationship for hotels. This result is counter-intuitive, as it implies that as a good becomes more expensive people want to buy more of it. However, one possible explanation could be the different source of the hotel data and composition of the Trivago price index. ${ }^{14}$

Finally, the results eliminating the major cities in Spain (Madrid and Barcelona) show similar results (model 6 in Table 3). We can say that the effect of the foreign hotel customer rate is positive and statistically significant. This may be due to the fact that it controls for potential different income effects between foreign and resident tourists.

In summary, it should be noted that our results could be different to some of the related empirical literature, which found that hotel occupancy falls after the arrival of AirBnb (Zervas et al 2017, for example). However, we should note that these studies focus only on city hotels and apply different empirical strategies (see limitations in Sect. 6).

Also, the study by Farronato and Fradkin (2017), the only study that, to date, estimates the effects of AirBnb's entry on hotel prices by using an identification model

\footnotetext{
${ }^{14}$ It should be noted that the overnight stays comes from a sample collected by the Spanish National Statistics Institute, while the price index covers all the hotels included in Trivago. These two sources do not necessarily match. In fact, the Trivago Hotel Price Index registers the average price per night on a monthly basis selected by the travellers (by clicking on them) for a standard double room https://busin essblog.trivago.com/es/tendencias-precios-hoteles/). It is also worth noting that one referee has pointed out about other possible causes for this counterintuitive result based on the treatment of data and the use of seasonal variables. We have conducted this analysis but results were always similar.
} 
Table 4 Long-run elasticities

\begin{tabular}{lll}
\hline Variables & AirBnb & Hotels \\
\hline ADR & 0.44 & 0.04 \\
Trivago hotel price index & 1.85 & 0.56 \\
AirBnb total beds $^{\mathrm{a}}$ & 0.14 & 0.01 \\
Hotel total beds $^{\mathrm{a}}$ & 0.71 & 1.52 \\
Foreign hotel customers rate & - & 0.06 \\
\hline
\end{tabular}

(a) Indicates that their values are evaluated at the mean of the variable in logs

(difference-in-difference estimations) and with a higher quality in the data ${ }^{15}$ and finds that although the effect on prices is negative (in other words, the hotels lower their prices with the entry of AirBnb), this is not the case of the higher category hotels. Further research on this specific question must be conducted.

In addition to the quality of the data mentioned, which differentiate this study from the one conducted by Farronato and Fradkin (2017), we must highlight two other fundamental aspects. First, our sample includes a wide variety of different types of hotel, such as the "sun and beach" tourism supply, while in the USA the hotels contemplated are mainly urban hotels. And second, the experience and development of AirBnb in the USA are much greater than in Spain. Furthermore, the time span of our database is shorter (in many cities less than 24 months have been studied).

A more recent paper by Roma et al. (2019) studies the price reaction of incumbents after AirBnb's entry into this market. The findings reveal a negative effect of the sharing economy's penetration on the prices of low-end consumers (1-3 stars hotels), but a positive one on those of high-end consumers (4-5 hotels). The authors explain that (cited literally) "(...) the rationale of this apparently counter-intuitive result is that the sharing economy puts strong pressure on high-end incumbents to reduce the prices for occasionally attracting deal-seekers to clear up capacity, which would be a strategy too inconsistent with their higher service quality, and would probably distance them away from their core business, i.e. high-end consumers".

\subsection{Long-run elasticities}

Although the period analysed is around three years (but with monthly data), we use the results of the dynamic panel data model to calculate the long-term elasticities in both AirBnb occupancy rates and hotel overnight stay models.

Table 3 shows the long-run elasticities for prices and supply using information from the estimated model 3 in Tables 2 and 3 and considering the general formula for prices $\hat{\beta}_{j} /\left(1-\hat{\alpha}_{1}\right)$, where the parameters $\hat{\beta}_{j}, j=1,2$ are the short-run price elasticities. In the case of beds, we calculate the long-run elasticities using the formula

\footnotetext{
15 The authors have information about hotel prices, level of occupancy, daily AirBnb supply, etc. In other words, the breakdown in terms of time and geography is much higher than shown here.
} 
$\left(\hat{\gamma}_{1}+2 \hat{\gamma}_{2} \overline{\log \text { beds }}\right) /\left(1-\hat{\alpha}_{1}\right)$, where $\hat{\gamma}_{1}$ and $\hat{\gamma}_{2}$ are the estimated short-run coefficients for $\log$ total beds and $(\log \text { total beds) })^{\wedge} 2$, and $\overline{\log \text { beds }}$ is the mean of the logarithm of beds (AirBnb or hotels).

In the case of AirBnb, the estimated short-run own-price elasticity in Table 2 is below 1, whereas in the long run (Table 4), the value is also below 1 (that is 0.44 , implying it is price-inelastic), which was unexpected. The exception is the Trivago index price for the AirBnb occupancy rate. The estimated short-run (e.g. 1.004) and long-run (e.g. 1.85) cross-price elasticities are positive and higher than one both in the short term and in the long term. This result shows that AirBnb and hotels are substitutes in the short and long term. In this context, price differentiation should provide an economic incentive for customers to change consumption patterns.

It is also noteworthy that the long-run elasticity (0.14\%) for AirBnb total beds is positive and slightly higher than the short-run $(0.081 \%)$, indicating a potential increase in AirBnb's offer in the future in different cities. (It should be remembered that the database corresponds to the period 2014-2017.)

\section{Policy implications and conclusions}

This paper seeks to further develop the study of the impact of tourist accommodation offered through the platform AirBnb on the local tourism markets in the principal cities of Spain. Although the existing research mainly focuses on the USA, empirical papers based on the European market have proliferated in recent years (see Sect. 2 of this paper). We should point out that the tourism activity and database of the USA are slightly different to those of Europe and Spain.

In this paper, we use a dynamic panel data model given that the panel data unit root test rejects the non-stationarity of the variables used in the estimated models. We investigate which factors drive AirBnb demand using a dynamic panel data model to account for the autocorrelation of occupancy rates and hotel overnight stays and focus both on AirBnb and on hotel supply. This is a supply-demand-driven model, where occupancy depends both on prices and supply.

The main results show not only a substitute relationship between AirBnb and hotels, but also that the greater number of beds offered by AirBnb has led to an increase in the total number of visitors received by this type of firms (due to higher AirBnb occupancy rates). This makes sense to the extent that these platforms are global, and therefore, the best-known destinations throughout the world are the first, a priori, to benefit. Therefore, restrictive policies against AirBnb and other similar digital platforms, especially in medium-sized and small cities, are not positive for tourism. Moreover, we find no effects of the AirBnb supply on total overnight stays at hotels.

Despite the limitations expressed in the study (see the following section), these results indicate the positive effects that the development of the peer-to-peer accommodation platforms has on the destination cities. Further research on this topic 
would require the minimisation of these limitations, subject to an improvement in the quality of the data, among other factors.

\section{Limitations and further research}

Estimating the causal effect of the entry of a new operator into a market requires a series of assumptions to be considered and methodologies to be implemented that enable these effects to be identified relatively clearly. Despite the novelty of the results presented, we can identify the following limitations and propose future lines of research:

1. Exogeneity in the entry.-the entry of AirBnb in a city is not random. That is, it probably responds to specific explanatory factors that encourage its entry which, therefore, should be considered in order to avoid biases in the estimates. These factors may include the stock of empty housing, the economic evolution at city level or the natural growth of the AirBnb phenomenon. However, none of this information is available on a city level or on a periodic time basis ${ }^{16}$; therefore, it cannot be used or estimated.

Other studies have attempted to approach this endogeneity of the model in a different way. For example, Farronato and Fradkin (2017) use quadratic time trends by city as instruments. This allows network effects to be monitored over time but imposes a growth model that is not necessarily shared by all of the cities and, furthermore, potentially coincides with the evolution of tourists in the cities which is why we have ruled this approach out.

We believe that this assumption affects the results presented in the study as the effect obtained is overvalued, but this does not invalidate it.

2. Detailed information about the accommodation supply and the level of observation. The study of these types of markets should not only be conducted on a local scale but should even be performed on a street-block-district level. Retail competition implies that if hotels and AirBnb do, in fact, compete, they do so in localisation. Eugenio-Martín et al. (2019) applied this spatial methodology to the Canary Islands (Spain), while Gutiérrez et al. (2017) did so for Barcelona as did the aforementioned studies for the USA (Zervas et al. 2017; Horn and Merante 2017; Farronato and Fradkin 2017; Gunter et al. 2020; among others).

In our case, the unit of observation is the city and the results shown are average values for each of them. In this way, we do not consider, for example, the effects on hotels of different categories (as do Farronato and Fradkin (2017), finding that the entry of AirBnb did not affect higher-category hotels), or those with different competitiveness pressures other than AirBnb.

\footnotetext{
16 The stock of empty housing can be estimated in Spain on a municipal level, but only with information from 2011 which has not been updated, rendering it unusable.
} 
3. Time period and short term. AirBnb arrived in Spain fairly recently, much later than in other cities such as San Francisco. The database that we have access to has, in the best of cases and only for Madrid and Barcelona, information dating back 39 months (a little more than three years), which limits the study of its impact. For the majority of cities, the available information dates back just 18 months and there is no single date of the entry of AirBnb in each city as all of the properties were not incorporated into the platform at the same time.

4. Quality of the information on a municipal level. The availability of information on a municipal level is scarce in Spain (see Ortuño and Jiménez 2019). For the objectives of this study, it would be necessary to use variables that control the level of local income, prices, used and free housing stock, etc. However, this information is not available, which could lead to the omission of relevant variables in some estimates.

5. Identification of effects and empirical strategy. This is perhaps the greatest limitation of the study. The ideal framework for conducting a causality study that enables the application of estimates of effects such as the difference-in-difference models, matching methods or similar methods, is the existence of a group of cities affected by the entry of AirBnb, another not affected and a clear moment in time that delimits the entry and divides the sample into a period before and a period after, if possible, an exogenous shock. (In this case, there is no shock according to above-described point 1.)

But, unfortunately, this ideal framework is not fulfilled for this study. On the one hand, as previously mentioned, the dates of entry of the new operator into each of the cities are not known. And, on the other hand, there is no control group which enables us to assess the differentiated effects between cities affected and those that are not. In the references for the USA market, as the analysis is conducted within each city, it is possible to delimit areas not affected by the entry of AirBnb, which serves as a control to study the evolution of those areas that have been affected (see Farronato and Fradkin 2017, for example).

Taking all of this into account, this study should be understood as a new contribution with respect to the academic literature in Europe, but subject to limitations which, while not invalidating the relationships between the variables and results, invite us to consider them as a preliminary approach to the analysis of this phenomenon in Spain.

\section{Appendix 1}

See Figs. 3, 4, 5, 6, 7, 8, 9, 10. 


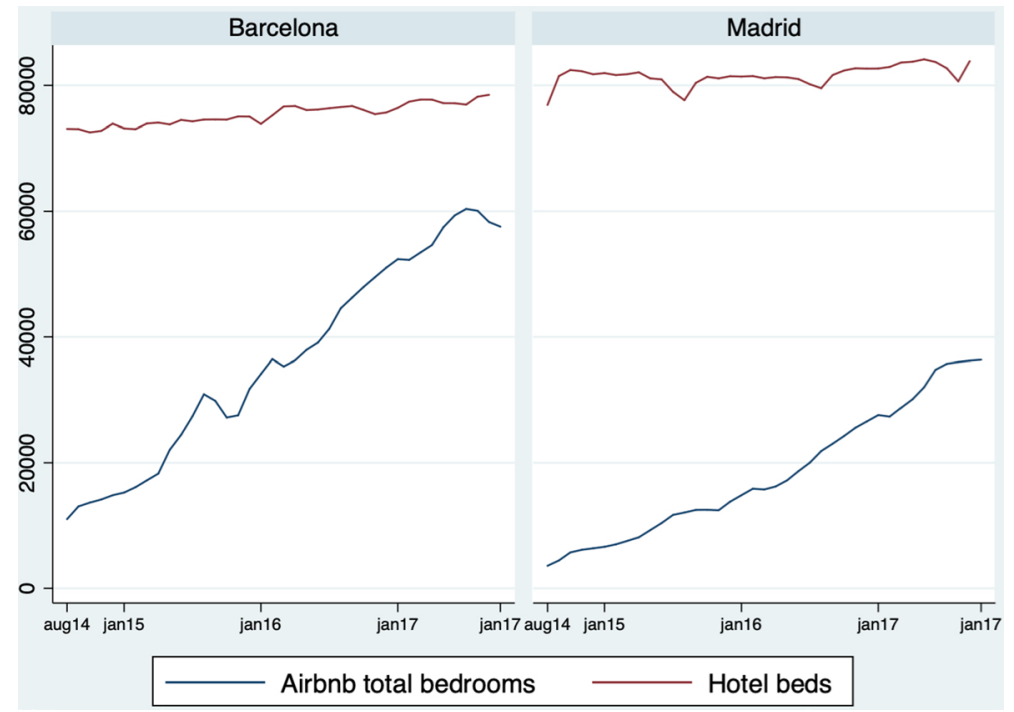

Fig. 3 Beds offered by AirBnb and estimated hotel beds (August 2014-October 2017). Barcelona and Madrid. Source: own elaboration based on data of Airdna and I.N.E

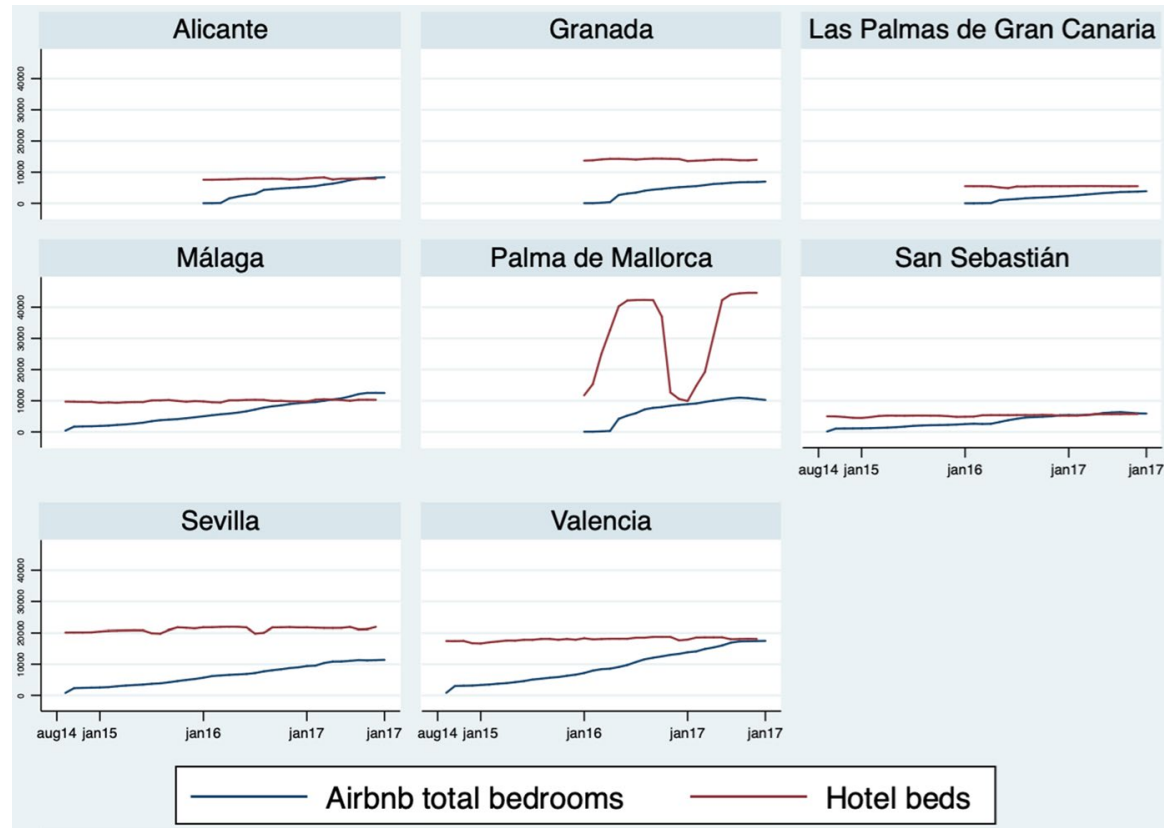

Fig. 4 Beds offered by AirBnb and estimated hotel beds in cities with an AirBnb supply of between three and ten thousand properties (August 2014-October 2017). Source: own elaboration based on data of Airdna and I.N.E 


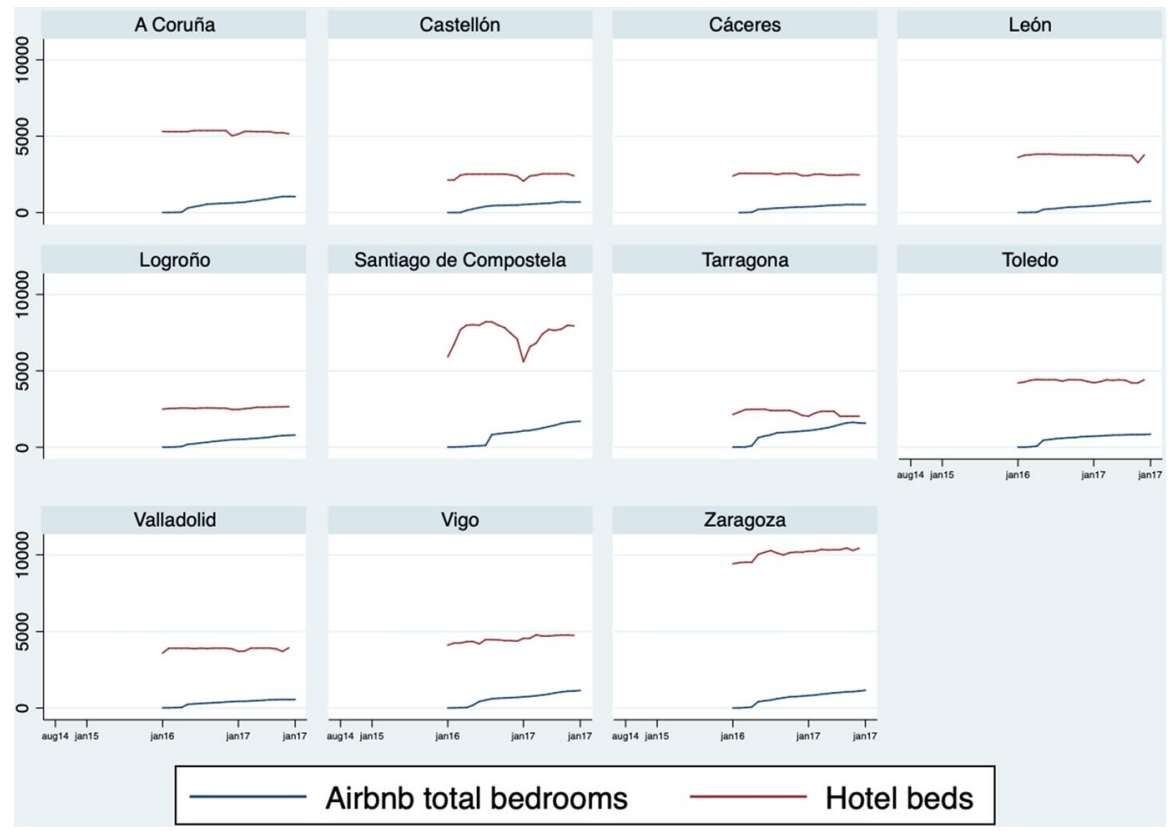

Fig. 5 Beds offered by AirBnb and estimated hotel beds in cities with an AirBnb supply of between one and two thousand properties (September 2015-October 2017). Source: own elaboration based on data of Airdna and I.N.E

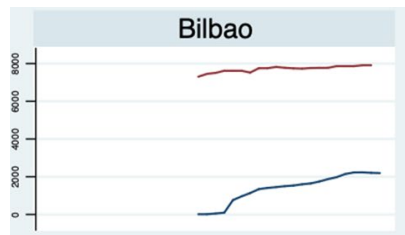

\section{Gijón}

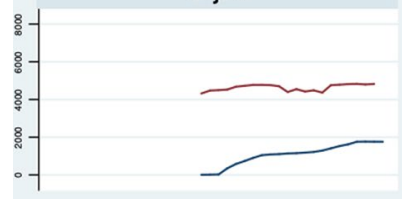

Salamanca

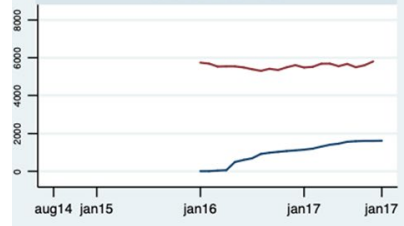

\section{Airbnb total bedrooms}

Cádiz

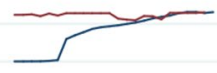

Murcia

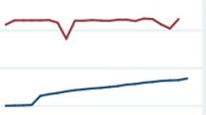

Santa Cruz de Tenerife
Córdoba

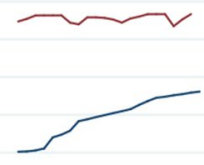

Pamplona

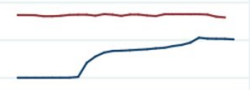

Santander

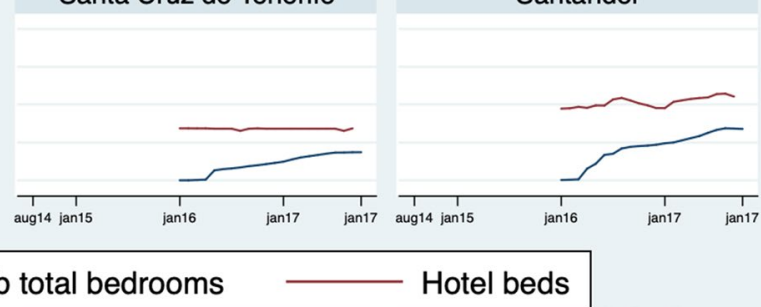

Fig. 6 Beds offered by AirBnb and estimated hotel beds in cities with an AirBnb supply of less than one thousand properties (January 2016-October 2017). Source: own elaboration based on data of Airdna and I.N.E 


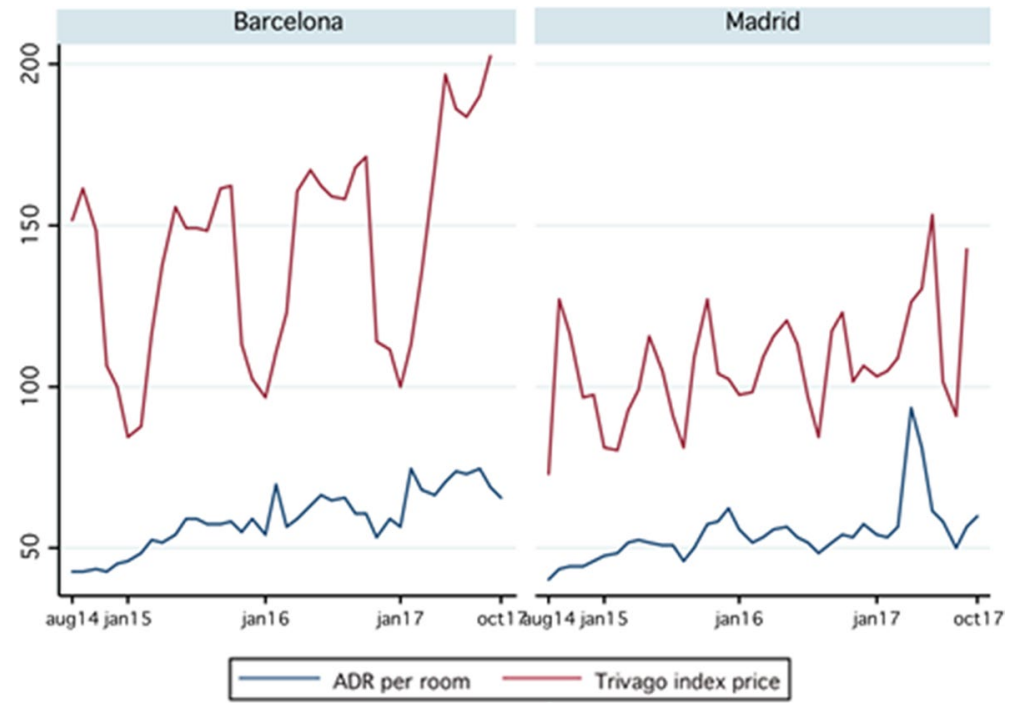

Fig. 7 ADR per AirBnb room and Trivago price index. Barcelona and Madrid (August 2014-October 2017). Source: own elaboration based on data of Airdna and I.N.E

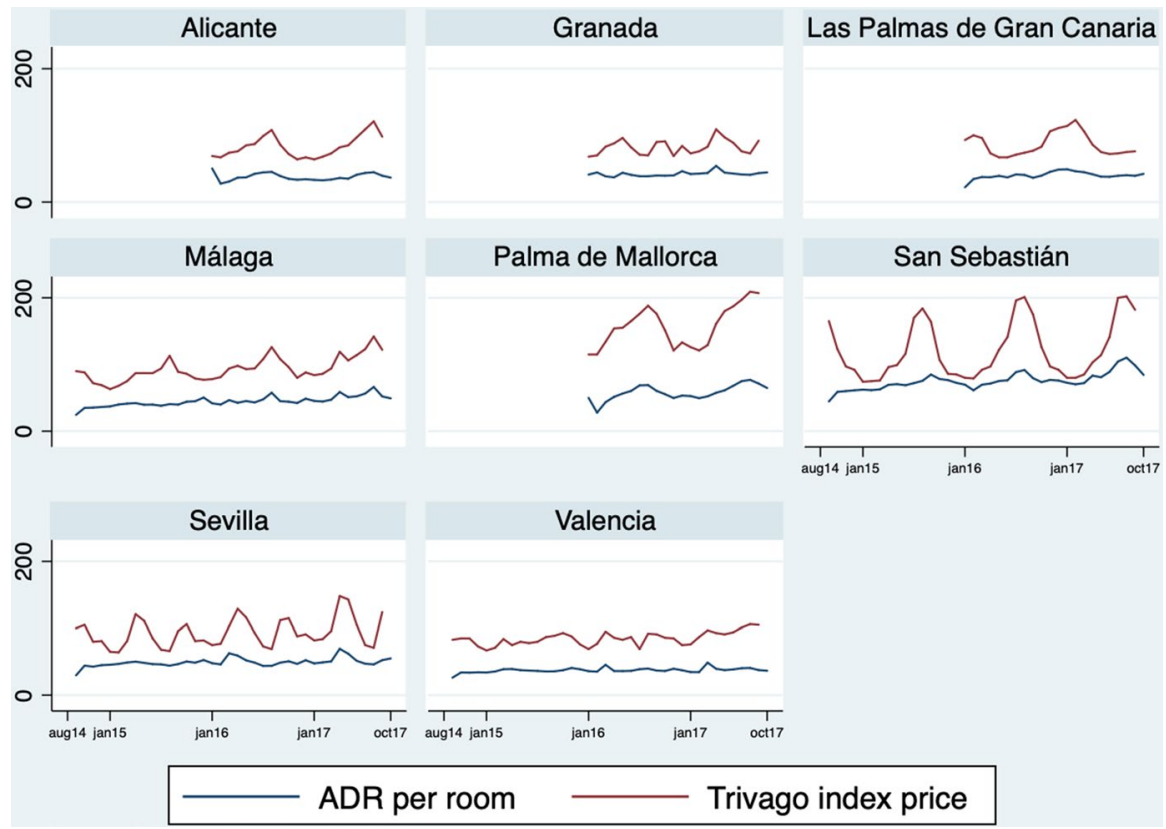

Fig. 8 ADR per AirBnb room and Trivago price index. Cities with an AirBnb supply of between three and ten thousand properties (August 2014-October 2017). Source: own elaboration based on data of Airdna and I.N.E 


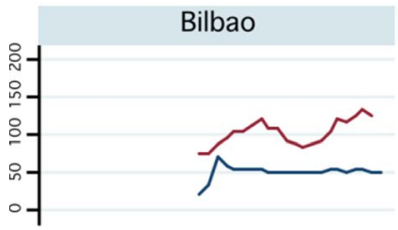

Gijón

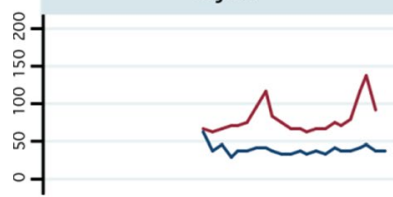

Salamanca

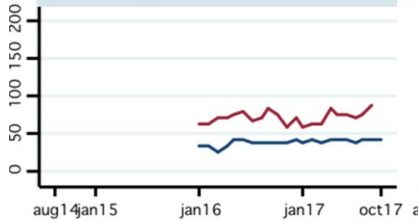

ADR per room
Cádiz

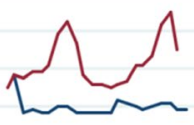

Murcia

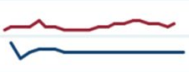

Santa Cruz de Tenerife

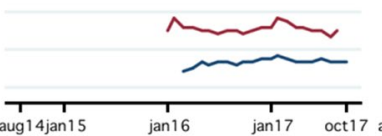

Trivago index price
Córdoba

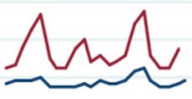

Pamplona

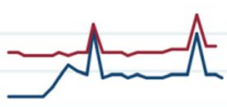

Santander

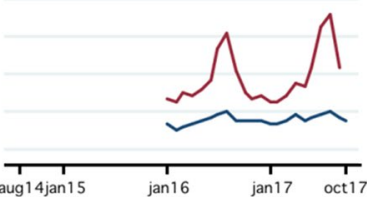

Fig. 9 ADR per AirBnb room and Trivago price index. Cities with an AirBnb supply of between one and two thousand properties (September 2015-October 2017). Source: own elaboration based on data of Airdna and I.N.E
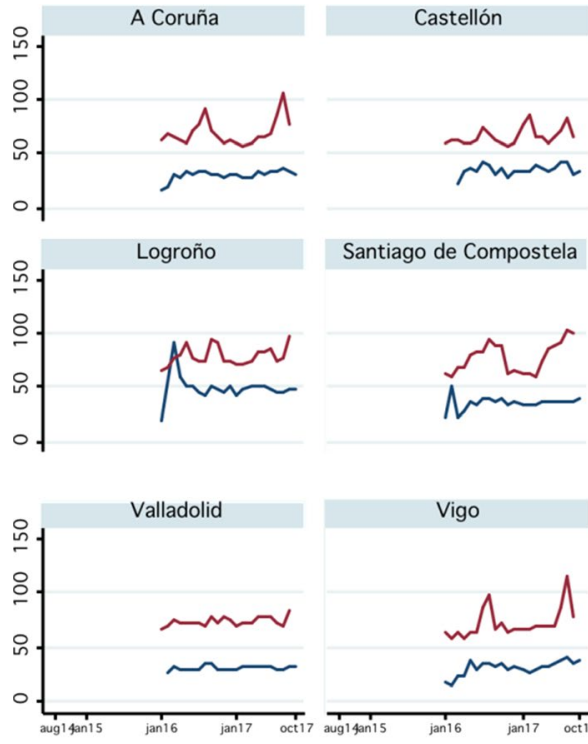

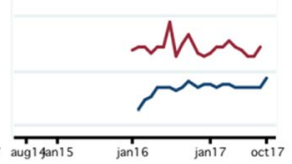

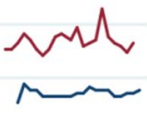

Tarragona
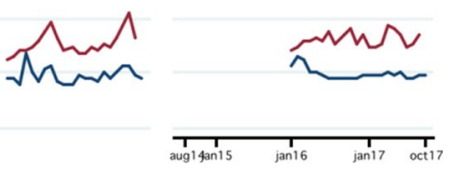

Zaragoza

León

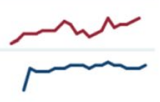

Toledo

Trivago index price

Fig. 10 ADR per AirBnb room and Trivago price index. Cities with an AirBnb supply of less than one thousand properties (August 2014-October 2017). Source: own elaboration based on data of Airdna and I.N.E 
Acknowledgements Armando Ortuño and Juan Luis Jiménez are grateful for the financial support received from the Fundación de Estudios de Economía Aplicada (FEDEA). The authors are grateful for the comments and suggestions made by two anonymous referees, and in a previous version of the paper by Joaquín Artés, Joan Ramón Borrell, Ángel de la Fuente, Ginés de Rus, Beatriz G. López-Valcárcel, Juan Luis Eugenio-Martín, Carmen García, and also the technical support from Rubén Ortuño, José Abreu and Javier Cruz. All errors are our own.

Funding Open Access funding provided thanks to the CRUE-CSIC agreement with Springer Nature. This study was partially funded by Fundación de Estudios de Economía Aplicada (grant 2019/04).

\section{Declarations}

Conflict of interest Authors declare that we have no conflict of interest.

Ethical approval This article does not contain any studies with human participants performed by any of the authors.

Open Access This article is licensed under a Creative Commons Attribution 4.0 International License, which permits use, sharing, adaptation, distribution and reproduction in any medium or format, as long as you give appropriate credit to the original author(s) and the source, provide a link to the Creative Commons licence, and indicate if changes were made. The images or other third party material in this article are included in the article's Creative Commons licence, unless indicated otherwise in a credit line to the material. If material is not included in the article's Creative Commons licence and your intended use is not permitted by statutory regulation or exceeds the permitted use, you will need to obtain permission directly from the copyright holder. To view a copy of this licence, visit http://creativecommons.org/licen ses/by/4.0/.

\section{References}

Adamiak C (2018) Mapping airbnb supply in European cities. Ann Tour Res 71:67-71

Arellano M, Bond S (1991) Some tests of specification for panel data: Monte Carlo Evidence and an application to employment equations. Rev Econ Stud 58:277-298

Barron, K, Kung, E, Proserpio, D (2017) The sharing economy and housing affordability: evidence from Airbnb. Available at SSRN: https://ssrn.com/abstract=3006832

Berry S, Levinsohn J, Pakes A (1995) Automobile prices in market equilibrium. Econometrica 63(4):841-890

Blundell R, Bond S (1998) Initial conditions and moment restrictions in dynamic panel data models. J Econom 87:115-144

Boto-García, D (2020) Habit formation in tourism traveling. J Travel Res, 1-17, forthcoming

Centre for Global Enterprise. (2016). The rise of the platform Enterprise. A global survey. Available at: https://www.thecge.net/app/uploads/2016/01/PDF-WEB-Platform-Survey_01_12.pdf

Cheng M, Zhang G (2019) When western hosts meet Eastern guests: Airbnb hosts' experience with Chinese outbound tourists. Ann Tour Res 75:288-303

Chortareas G, Kapetanios G (2009) Getting PPP right: identifying mean-reverting real exchange rates in panels. J Bank Finance 33:390-404

Coles P, Egesdal M, Gould Ellen I, Li X, Sundararajan A, forthcoming. Airbnb usage across New York City neighborhoods: geographic patterns and regulatory implications. Cambridge handbook of the Law of the sharing economy. Available at: https://ssrn.com/abstract=3048397

Coyle D, Yeung T (2016) Understanding Airbnb in fourteen European cities. The Jean-Jacques Laffont Digital Chair Working Papers.

Dogru T, Makarand M, Suess C (2019) Adding evidence to the debate: quantifying Airbnb's disruptive impact on ten key hotel markets. Tour Manage 72:27-38

Dolnicar S (ed) (2017) Peer-to-peer accommodation networks: pushing the boundaries. Goodfellow Publishers, Oxford 
Ert E, Fleischer A (2019) The evolution of trust in Airbnb: a case of home rental. Ann Tour Res 75:279-287

Eugenio-Martín, JL, Cazorla-Artiles, JM González-Martel, C (2019) On the determinants of Airbnb location and its spatial distribution. Tourism Econ, 1-21, In press

Exceltur (2016) Observaciones al Estudio de la CNMC sobre nuevos modelos de prestaciones de servicios y la Economía colaborativa (E/CNMC/004/15)

Farronato C, Fradkin A (2017) The welfare effects of peer entry in the accommodation market: the case of Airbnb. Mimeo

Gunter U, Önder I, Zekan B (2020) Modeling Airbnb demand to New York City while employing spatial panel data at the listing level. Tourism Manag, 77, forthcoming. DOI: https://doi.org/10. 1016/j.tourman.2019.104000

Gunter U, Önder I (2018) Determinants of Airbnb demand in Vienna and their implications for the traditional accommodation industry. Tour Econ 24:270-293

Gurran N, Phibbs P (2017) When tourists move in: how should urban planners respond to Airbnb. J Am Plan Assoc, 83(1): 80-92

Gutiérrez J, García-Palomares JC, Romanillos G, Salas-Olmedo MH (2017) The eruption of Airbnb in tourist cities: comparing spatial patterns of hotels and peer-to-peer accommodation in Barcelona. Tour Manage 62:278-291

Guttentag D, Smith SLJ (2017) Assessing Airbnb as a disruptive innovation relative to hotels: substitution and comparative performance expectations. Int J Hosp Manag 67:1-10

Gyódi K (2019) Airbnb in European cities: business as usual or true sharing economy? J Clean Prod 221:536-551

Hajibaba H, Dolnicar S (2017) Regulatory reactions around the world. In: Dolnicar S (ed) Peer-topeer accommodation networks. Goodfellow Publishers, Oxford, pp 120-136. https://doi.org/10. 23912/9781911396512-3609

Heckman JJ (1981a) The incidental parameters problem and the problem of initial conditions in estimating a discrete time-discrete data stochastic process. In: Manski CF, McFadden DL (eds) Structural analysis of discrete data with econometric applications. MIT Press, Cambridge, MA, pp 179-195

Heckman JJ (1981b) Heterogeneity and state dependence. In: Sherwin R (ed) Studies in Labor Markets. University of Chicago Press, Chicago, pp 91-140

Heo CY, Blal I, Choi M (2019) What is happening in Paris? Airbnb, hotels, and the Parisian market: a case study. Tour Manage 70:78-88

Horn K, Merante M (2017) Is home sharing driving up rents? Evidence from Airbnb in Boston. J Hous Econ 38:14-24

Huarng KH, Yu MF (2019) Customer satisfaction and repurchase intention theory for the online sharing economy. Rev Manag Sci 13(3):635-647

Jordan EJ, Moore J (2018) An in-depth exploration of residents' perceived impacts of transient vacation rentals. J Travel Tour Mark 35(1):90-101

Liang S, Schuckert M, Law R, Chen CC (2020) The importance of marketer-generated content to peerto-peer property rental platforms: Evidence from Airbnb. Int J Hospitality Manag 84:102329

Instituto Nacional de Estadística (2019). Available at: http://www.ine.es/jaxiT3/Tabla.htm?t=2078

Neeser D (2015) Does Airbnb hurt hotel business: Evidence from the Nordic countries. Master Thesis, Universidad Carlos III de Madrid

$\mathrm{Ng} \mathrm{S}$ (2008) A simple test for non-stationarity in mixed panels. J Business Econ Stat 26:113-127

Nowak B, Allen T, Rollo J, Lewis V, He L, Chen A, Wilson WN, Costantini M, Hyde O, Liu K, Savino M, Chaudhry BA, Grube AM, Young E, (2015) Global insight: Who will Airbnb hurt more-hotels or OTAs? Morgan Stanley Research

Ortuño A, Jiménez JL (2019) Las viviendas turísticas ofertadas por plataformas on-line: estado de la cuestión. Documento de Trabajo 2019/04. FEDEA

Pesaran MH, Shin Y, Smith RP (1999) Pooled mean group estimation of dynamic heterogeneous panels. J Am Stat Assoc 94:621-634

Pesaran MH, Shin Y, Smith RP (1997) Estimating long-run relationships in dynamic heterogeneous panels. DAE Working Papers Amalgamated Series 9721

Quattrone, G., Proserpio, D., Quercia, D., Capra, L., and Musolesi, M. 2016. Who benefits from the "sharing" economy of Airbnb? Proceedings of the 25th International Conference on World Wide Web, 1385-1394. 
Roma P, Panniello U, Lo Nigro G (2019) Sharing economy and incumbents' pricing strategy: the impact of Airbnb on the hospitality industry. Int J Prod Econ 214:17-29

Santana-Gallego M, Ledesma-Rodríguez F, Pérez-Rodríguez JV (2011) Tourism and trade in OECD countries. A dynamic heterogeneous panel data analysis. Empirical Econ 41(2):533-554

Sheppard S, Udell A. (2016) Do Airbnb properties affect house prices? Mimeo

Song H, Witt S (2000) Tourism demand modelling and forecasting. Pergamon, Amsterdam

Tussyadiah P, Pesonen J (2016) Impacts of peer-to-peer accommodation use on travel patterns. J Travel Res 55(8):1022-1040

Volgger M, Taplin R, Pforr C (2019) The evolution of 'Airbnb-tourism': demand-side dynamics around international use of peer-to-peer accommodation in Australia. Ann Tour Res 75:322-337

Wang D, Nicolau JL (2017) Price determinants of sharing economy based accommodation rental: a study of listings from 33 cities on Airbnb.com. Int J Hosp Manag 62:120-131

Wegmann J, Jiao J (2017) Taming Airbnb: toward guiding principles for local regulation of urban vacation rentals based on empirical results from five US cities. Land Use Policy 69:494-501

Windmeijer F (2005) A finite sample correction for the variance of linear efficient two-step GMM estimators. J Econ 126:25-51

Zervas G, Proserpio D, Byers JW (2017) The rise of the sharing economy: estimating the impact of Airbnb on the hotel industry. J Market Res 2:687-705

Zhang M, Li J, Pan B, Zhang G (2018) Weekly hotel occupancy forecasting of a tourism destination. Sustainability 10:4351

Zhu Y, Cheng M, Wang J, Ma L, Jiang R (2019) The construction of home feeling by Airbnb guests in the sharing economy: a semantics perspective. Ann Tour Res 75:308-321

Publisher's Note Springer Nature remains neutral with regard to jurisdictional claims in published maps and institutional affiliations. 